\title{
Possibilities of Experimental Modulation of Senescence by Stimulation of Antiradical Defense
}

\author{
Manuela Ciocoiu1, Magda Badescu1 ${ }^{*}$, Oana Badulescu', Madalina Mocanu1, \\ Codruta Badescu ${ }^{2}$ \\ ${ }^{1}$ Department of Pathophysiology, Faculty of Medicine, University of Medicine and Pharmacy “Grigore T. Popa”, \\ lasi, Romania \\ ${ }^{2}$ Internal Medicine Clinic, St. Spiridon Hospital, University of Medicine and Pharmacy "Grigore T. Popa”, Iasi, \\ Romania \\ Email: ${ }^{*}$ magda.badescu@gmail.com
}

Received 10 March 2015; accepted 4 April 2015; published 8 April 2015

Copyright (C) 2015 by authors and Scientific Research Publishing Inc.

This work is licensed under the Creative Commons Attribution International License (CC BY).

http://creativecommons.org/licenses/by/4.0/

(c) (i) Open Access

\begin{abstract}
Various epidemiological studies have shown an inverse association between the consumption of polyphenols or polyphenol-rich foods and the risk of neurodegenerative, hepatic diseases. The research aimed to fight oxidative stress and lipid metabolism changes in the context of administration of antioxidants, such as polyphenolic extract of Aronia melanocarpa and zinc aspartate, known for its neurotrophic effects in intrinsic aging processes. Zinc aspartate and polyphenolic extract from Aronia melanocarpa reduce oxidative stress values both in serum, liver homogenate, and in brain homogenate. Oxidative stress assessed by malondialdehyde (MDA), glutathione peroxidase (GPX) and total antioxidant capacity (TAC) markers was reduced in animals receiving additional zinc salts and polyphenolic extract of Aronia melanocarpa, which underlines their role in antioxidant defense. This combination produces more superior hypolipidemic and antioxidant effects than in the case of separate administration within experimental senescence induced in the murine model. Further studies will investigate the effect of different dose combinations of zinc aspartate and polyphenolic extract of Aronia melanocarpa at different periods of treatments on age-associated liver/cerebral dysfunction.
\end{abstract}

\section{Keywords}

Senescence, Zinc Aspartate, Aronia melanocarpa, Oxidative Stress

\footnotetext{
"Corresponding author.
}

How to cite this paper: Ciocoiu, M., Badescu, M., Badulescu, O., Mocanu, M. and Badescu, C. (2015) Possibilities of Experimental Modulation of Senescence by Stimulation of Antiradical Defense. J. Biomedical Science and Engineering, 8, 237245. http://dx.doi.org/10.4236/ibise.2015.84023 


\section{Introduction}

Early identification of senescence and neurodegenerative diseases markers or susceptibility for their existence, carried out in order to implement actions targeted at prevention has been a priority for medical research. Oxidative stress is proposed as a key element in the aging process [1], when vulnerability to oxidative stress and inflammation increases. Furthermore, oxidant and antioxidant status may also cause the degenerative changes encountered in aging. Most dietary agents used to alter behavioral and neuronal effects with aging included nutritional supplements such as vitamins C and E, garlic [2], herbal supplements (e.g. ginseng, Ginkgo biloba) [3], and dietary fatty acids [4].

The turnover of zinc (Zn) in the brain is slower than that in the liver and in other peripheral tissues, and this is due to the presence of blood-brain barrier. This system of barriers is important for $\mathrm{Zn}$ homeostasis in the brain and its alteration may be associated with brain dysfunctions and neurological diseases [5] [6]. The natural polyphenolic compound resveratrol (3,5,4'-trihydroxystilbene) has emerged as a still-debatable mediator of longevity that certainly delays or attenuates many age-related chronic diseases in animal models [7]-[10]. It is important to describe the possible role of nutritional supplementation with fruits containing large amounts of polyphenols, such as anthocyanins, in reversing or forestalling senescence deficits.

The research aimed to fight oxidative stress and lipid metabolism changes in the context of administration of antioxidants, such as polyphenolic extract of Aronia melanocarpa and Zn aspartate, known for its neurotrophic effects in intrinsic aging processes.

\section{Material and Method}

The experimental study fulfils all the requirements of the guide regarding the use of laboratory animals and biological preparations issued by the International Society of Pain Study (IASP) and the European Council Committee (86/609/EEC). Also, the study was evaluated and accepted by the professional ethics committee of Grigore T. Popa University of Medicine and Pharmacy of Iasi (9803/12.09.2006).

The experimental model on white Wistar rats of different ages aimed to perform an analysis of some biochemical parameters under chronological age standardized conditions. The research was carried out on Wistar white male rats, aged 30 months at the beginning of the study, weighing 250 - $280 \mathrm{~g}$ on the average, which were divided into 4 groups of 12, namely: Group $\mathbf{Z n}$-white rats, Wistar rats, aged, who were administered Zn aspartate $0.070 \mathrm{~g} / \mathrm{kg}$ body weight, p.o. (by tube feeding) for 16 weeks; Group A-Wistar white rats, aged, who were administered an A. melanocarpa polyphenolic extract $0.050 \mathrm{~g} / \mathrm{kg}$ body weight p.o. (by tube feeding) every two days for 16 weeks; the dry polyphenol extract was diluted in DMSO, $100 \mathrm{~mL}$ polyphenolic solution containing $840 \mathrm{mg}$ natural polyphenols, $95 \mathrm{~mL}$ distilled water and $5 \mathrm{~mL}$ DMSO; Group $\mathbf{Z n}+\mathbf{A}-$ Wistar white rats, aged, simultaneous administration of $\mathrm{Zn}$ and polyphenolic extract in specified doses for 16 weeks; Group $\mathbf{W}$, control rats-Wistar white rats, males aged 30 months, treated with saline vehicle for 16 weeks.

Animals were sacrificed 4 months later by anesthesia with thiopental, in a dose of $1 \mathrm{ml} / 100 \mathrm{~g}$ out of $0.01 \%$ thiopental solution. After anesthetizing the animal with thiopental, the ribcage was opened and heart punctured to collect blood. After the disappearance of vital signs (breathing, heartbeat), fragments of organs for biochemical tests were collected: fragments of rat liver and brain, for liver and brain homogenates. The liver and brain were washed in ice-cold saline, blotted dry, weighed and homogenized in ice-cold physiological saline. Liver and brain homogenates were divided into portions and stored at $-70^{\circ} \mathrm{C}$ until analyzed.

The malondialdehyde (MDA) concentration - the index of lipid peroxidation — was determined by the Ohkawa method using the tiobarbituric acid [11]. The MDA concentration was expressed in $\mathrm{nmol} / \mathrm{mL}$.

Glutathione peroxidase (GSH-Px) $\left(\mathrm{H}_{2} \mathrm{O}_{2}\right.$ : GSH oxidoreductase) was determined by the Gross and Beutler method [12]; the GSH-Px activity was expressed in $\mu \mathrm{M}$ oxidized GSH per minute/g Hb or mg protein.

For the extracellular response the total antioxidant capacity (TAC) was determined by using a RANDOX kit for manual use by Randox Laboratories Ltd. The major advantage of this test is to measure the antioxidant capacity of all antioxidants in a biological sample and not just the antioxidant capacity of a single compound. The method is based on formation of the $\mathrm{ABTS}^{*+}$ cation [2,2'-azinobis(3-ethylbenzothiazoline-6-sulfonic acid)] and its scavenging by antioxidant sample constituents (e.g., serum or food) measured by spectrophotometry (decay of green/blue chromophore absorbance is inversely associated with antioxidant sample content and the control antioxidant is Trolox, a hydrophilic vitamin $\mathrm{E}$ analog).

Serum total cholesterol, HDL-cholesterol and triglycerides were measured by enzymatic colorimetric me- 
thods on a TECAN micro plate reader by commercially available kits (Audit Diagnostics Ireland). Non-HDL cholesterol was calculated by subtracting HDL cholesterol from total cholesterol. $\mathbf{L D L}$ and $\boldsymbol{V} \boldsymbol{L D L}$ calculation. Low density lipoproteins (LDL and VLDL) and Chylomicrons are precipitated by PEG 6000 buffer.

Statistical data interpretation. All the data are shown as mean value \pm standard error of the mean. Data were loaded and processed using statistical functions of EPIINFO 6.0, SPSS 13.0 and EXCEL. ANOVA and paired or unpaired t-test reveal the pairs of groups that differ in a biostatistical significant way in terms of means. Statistical data interpretation considered the corresponding differences for a given significance threshold: $\mathrm{p}>0.05$ statistically insignificant; $\mathrm{p}<0.05$ statistically significant; $\mathrm{p}<0.01$ strong statistical significance; $\mathrm{p}<0.001$ very strong statistical significance.

\section{Results}

Applying the ANOVA test to the series of values recorded for serum cholesterol, the following aspects were reported: the variance rate is within wide limits, ranging from $8.07 \%$ in group $\mathrm{Zn}+\mathrm{A}$ to $22.65 \%$ in group $\mathrm{W}$; the most homogeneous values were recorded in group $\mathrm{Zn}+\mathrm{A}$ (Figure 1). By applying the Student t-test to mean values of serum cholesterol comparatively by lots, no statistically significant differences were recorded in the study groups $(\mathrm{p}>0.005)$.

In all study groups, mean values of HDL-cholesterol (HDL-chol) are significantly lower than in W group ( $\mathrm{p}<$ 0.001). In serum, HDL-chol mean values ranged from 23.96 and $41.89 \mathrm{mg} / \mathrm{dl}$ and significantly higher average values were found in $\mathrm{W}$ group compared to other study groups $(\mathrm{p}<0.001)$ (Table 1$)$.

In all study groups, mean values of LDL-cholesterol (LDL-chol) are significantly lower than in group W ( $<<$ 0.001). In serum, mean values of LDL-cholranged between 71.59 and $74.46 \mathrm{mg} / \mathrm{dl}$ without showing significant differences between the study groups ( $\mathrm{p}>0.05$ ) (Table 2). $\mathrm{Zn}, \mathrm{A}$ and $\mathrm{Zn}+\mathrm{A}$ do not significantly alter the values of LDLc in serum.

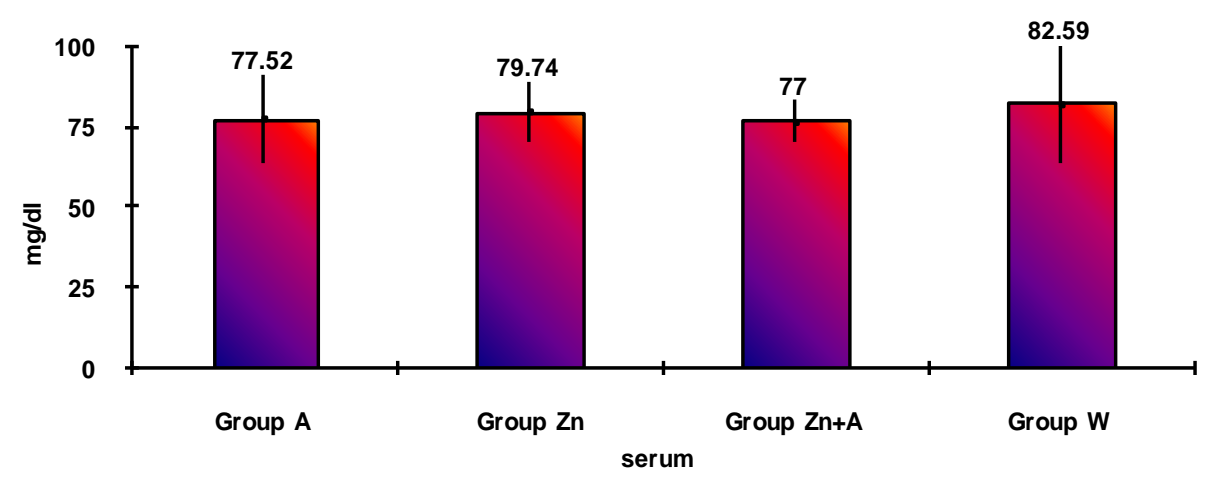

Figure 1. Mean values of cholesterol by study groups.

Table 1. Statistical significance of differences in mean values of HDL-chol in serum by study groups compared to control group.

\begin{tabular}{cccc}
\hline HDL-chol & Lot $\mathbf{A}$ & Lot $\mathbf{Z n}$ & Lot Zn $+\mathbf{A}$ \\
\hline Lot Zn & $1.85 ; \mathrm{p}>0.05$ & & \\
Lot Zn + A & $1.46 ; \mathrm{p}>0.05$ & $0.74 ; \mathrm{p}>0.05$ & \\
Lot W & $\mathbf{2 2 . 5 7} \mathbf{p}<\mathbf{0 . 0 0 1}$ & $\mathbf{2 3 . 1 2} \mathbf{p}<\mathbf{0 . 0 0 1}$ & $\mathbf{2 9 . 4 1 ;} \mathbf{p}<\mathbf{0 . 0 0 1}$ \\
\hline
\end{tabular}

Table 2. Statistical significance of differences in mean values of LDL-chol in serum by study groups compared to control group.

\begin{tabular}{cccc}
\hline LDL-chol & Lot $\mathbf{A}$ & Lot Zn & Lot Zn $+\mathbf{A}$ \\
\hline Lot Zn & $0.60 ; \mathrm{p}>0.05$ & \\
Lot Zn + A & $0.08 ; \mathrm{p}>0.05$ & $0.95 ; \mathrm{p}>0.05$ & \\
Lot W & $\mathbf{0 . 2 5} ; \mathbf{p}>\mathbf{0 . 0 5}$ & $\mathbf{0 . 2 0} ; \mathbf{p}>\mathbf{0 . 0 5}$ & $\mathbf{0 . 2 6} ; \mathbf{p}>\mathbf{0 . 0 5}$ \\
\hline
\end{tabular}


Mean values of triglycerides (TG) in serum ranged between 93.40 and $163.32 \mathrm{mg} / \mathrm{dl}$ and significantly lower mean values were found in groups Zn ( $p<0.001)$, A and $\mathrm{Zn}+\mathrm{A}(\mathrm{p}<0.001)$ compared to group W (Figure 2). There are no statistically significant differences between groups $\mathrm{Zn}, \mathrm{A}$ and $\mathrm{Zn}+\mathrm{A}$.

Malondialdehyde (MDA) was investigated in the 4 groups in serum, liver and brain homogenates (Figure 3). Applying the Student t-test to mean values of MDA comparatively by study groups, the following aspects were reported: after administration of A and Zn, serum MDA mean values were significantly lower in Zn groups ( $\mathrm{p}<$ 0.001), A ( $p<0.001)$ and $\mathrm{Zn}+\mathrm{A}(\mathrm{p}<0.001)$ compared to group $\mathrm{W}$. The strongest effect of reducing the level of oxidative stress in serum is associated with $\mathrm{Zn}$ group, compared to group $\mathrm{W}$ (Table 3 ). In liver homogenate, the mean values of MDA are significantly lower in rats in group $\mathrm{Zn}(\mathrm{p}<0.001)$ and $\mathrm{Zn}+\mathrm{A}(\mathrm{p}<0.001)$ compared to group $\mathrm{W}$. The highest values of MDA in brain homogenate were recorded in $\mathrm{W}$ group, significantly higher compared to groups $\mathrm{Zn}$ and $\mathrm{Zn}+\mathrm{A}(\mathrm{p}<0.001)$ (Table 4).

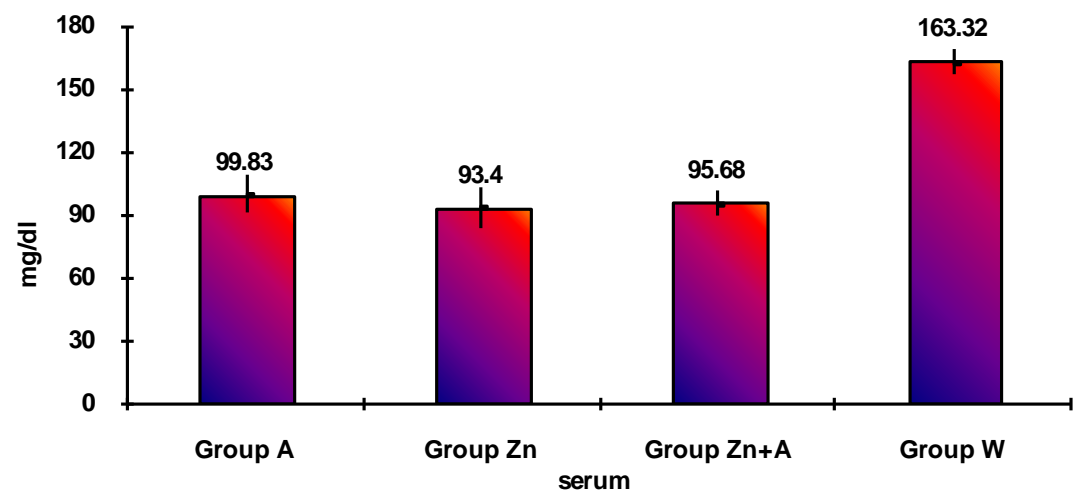

Figure 2. Mean values of triglycerides by study groups.
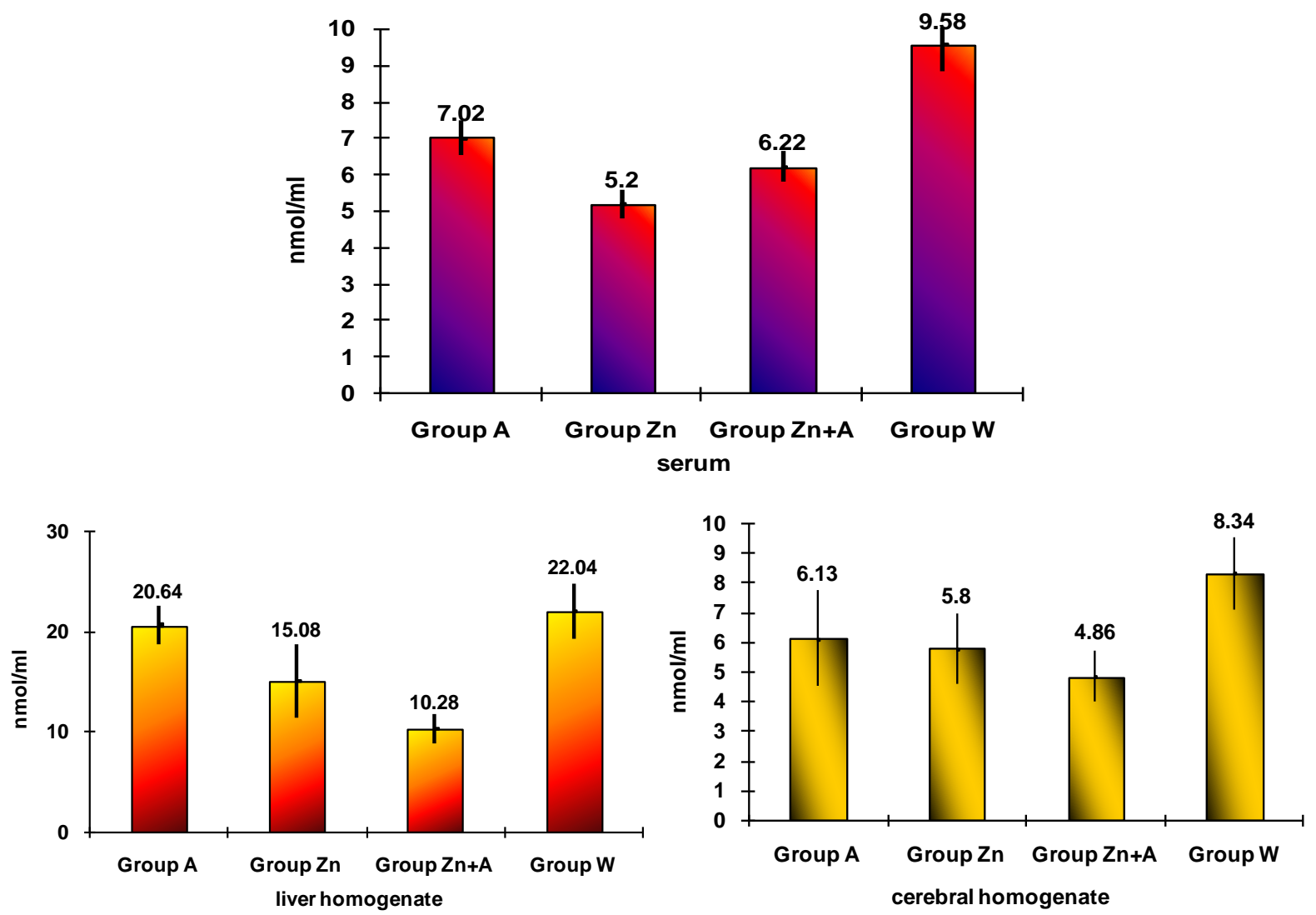

Figure 3. Mean values of MDA by study groups. 
Glutathione peroxidase (GPx) was investigated in whole blood, plasma, liver and brain homogenates. Applying the ANOVA test to the series of values recorded for GPx, the following aspects were reported: mean values of GPx in whole blood and plasma were significantly lower ( $<<0.001)$ in groups A, Zn şi Zn + A compared to group W (Table 5); mean values of GPx from liver (Table 6) and brain homogenates (Table 7) were also significantly lower $(\mathrm{p}<0.001)$ in groups treated with $\mathrm{A}$, $\mathrm{Zn}$ and $\mathrm{Zn}+\mathrm{A}$, compared to group $\mathrm{W}$.

Total Antioxidant Capacity (TAC) was studied for the4 groups in serum and liver homogenate (Table 8). Applying Student t-test average values of TAC, comparatively by study groups, showed the following aspects: in serum, the lowest mean value was recorded in group W ( $<0.05)$, and the highest mean value in group A (p $<0.002$ ), statistically significant differences; in liver homogenate, mean values of TAC in Zn group were significantly higher than in other groups $(\mathrm{p}<0.001)$, the lowest means were recorded in group A, significantly lower than in $\mathrm{Zn}$ and $\mathrm{Zn}+\mathrm{A}(\mathrm{p}<0.001)$. The mean values of the TAC were increased in groups treated with $\mathrm{A}$ and $\mathrm{Zn}+\mathrm{A}$, compared to group $\mathrm{W}$.

Table 3. Statistical significance of differences in mean values of MDA by study lot in serum and liver homogenate.

\begin{tabular}{|c|c|c|c|c|c|}
\hline MDA & Lot A & Lot Zn & Lot $\mathbf{Z n}+\mathbf{A}$ & Lot W & \\
\hline Lot A & - & $5.19 \mathbf{p}<\mathbf{0 . 0 0 1}$ & $16.44 \mathbf{p}<\mathbf{0 . 0 0 1}$ & $1.61 \mathrm{p}>0.05$ & \multirow{4}{*}{ liver homogenate } \\
\hline Lot Zn & $11.78 \mathbf{p}<\mathbf{0 . 0 0 1}$ & - & $4.74 \mathbf{p}<\mathbf{0 . 0 0 1}$ & $5.91 \mathbf{p}<\mathbf{0 . 0 0 1}$ & \\
\hline Lot Zn + A & $4.86 \mathbf{p}<\mathbf{0 . 0 0 1}$ & $6.96 \mathbf{p}<\mathbf{0 . 0 0 1}$ & - & $14.76 \mathbf{p}<\mathbf{0 . 0 0 1}$ & \\
\hline Lot W & $11.10 \mathbf{p}<\mathbf{0 . 0 0 1}$ & $20.07 \mathbf{p}<\mathbf{0 . 0 0 1}$ & $14.90 \mathbf{p}<\mathbf{0 . 0 0 1}$ & - & \\
\hline
\end{tabular}

Table 4. Statistical significance of differences in mean values of MDA by study lot—in serum and brain homogenate.

\begin{tabular}{|c|c|c|c|c|c|}
\hline MDA & Lot AGP n3 & Lot ACC & Lot ACC+AGP n3 & Lot W & \\
\hline Lot A & - & $0.64 p>0.05$ & $2.71 \mathbf{p}<\mathbf{0 . 0 5}$ & $4.27 \mathbf{p}<\mathbf{0 . 0 0 1}$ & \multirow{5}{*}{ brain homogenate } \\
\hline Lot Zn & $11.78 \mathbf{p}<\mathbf{0 . 0 0 1}$ & - & $2.48 \mathbf{p}<\mathbf{0 . 0 5}$ & $5.80 \mathbf{p}<\mathbf{0 . 0 0 1}$ & \\
\hline Lot $\mathbf{Z n}+\mathbf{A}$ & $4.86 \mathbf{p}<\mathbf{0 . 0 0 1}$ & $6.96 \mathbf{p}<\mathbf{0 . 0 0 1}$ & - & $9.08 \mathbf{p}<\mathbf{0 . 0 0 1}$ & \\
\hline Lot W & $11.10 \mathbf{p}<\mathbf{0 . 0 0 1}$ & $20.07 \mathbf{p}<\mathbf{0 . 0 0 1}$ & $14.90 \mathbf{p}<\mathbf{0 . 0 0 1}$ & - & \\
\hline & & serum & & & \\
\hline
\end{tabular}

Table 5. Statistical significance of differences in mean values of GPx by study groups-in whole blood and plasma.

\begin{tabular}{c|ccccc}
\hline GPx & Lot $\mathbf{A}$ & Lot Zn & Lot Zn $+\mathbf{A}$ & Lot W \\
\hline Lot $\mathbf{A}$ & - & $9.67 \mathbf{p}<\mathbf{0 . 0 0 1}$ & $13.95 \mathbf{p}<\mathbf{0 . 0 0 1}$ & $7.51 \mathbf{p}<\mathbf{0 . 0 0 1}$ \\
Lot Zn & $7.90 \mathbf{p}<\mathbf{0 . 0 0 1}$ & - & $8.63 \mathbf{p}<\mathbf{0 . 0 0 1}$ & $13.47 \mathbf{p}<\mathbf{0 . 0 0 1}$ & plasma \\
Lot Zn $+\mathbf{A}$ & $4.08 \mathbf{p}<\mathbf{0 . 0 0 1}$ & $12.18 \mathbf{p}<\mathbf{0 . 0 0 1}$ & - & $16.86 \mathbf{p}<\mathbf{0 . 0 0 1}$ \\
Lot $\mathbf{W}$ & $8.02 \mathbf{p}<\mathbf{0 . 0 0 1}$ & $13.36 \mathbf{p}<\mathbf{0 . 0 0 1}$ & $5.77 \mathbf{p}<\mathbf{0 . 0 0 1}$ & - \\
& & whole blood & & \\
\hline
\end{tabular}

Table 6. Statistical significance of differences in mean values of GPx by study groups-in liver homogenate.

\begin{tabular}{cccc}
\hline GPx & Lot $\mathbf{A}$ & Lot Zn & Lot Zn $+\mathbf{A}$ \\
\hline Lot $\mathbf{A}$ & - & & \\
Lot Zn & $36.71 \mathbf{p}<\mathbf{0 . 0 0 1}$ & - & - \\
Lot Zn + A & $2.78 \mathbf{p}<\mathbf{0 . 0 1}$ & $25.64 \mathbf{p}<\mathbf{0 . 0 0 1}$ & $13.28 \mathbf{p}<\mathbf{0 . 0 0 1}$ \\
Lot $\mathbf{W}$ & $16.11 \mathbf{p}<\mathbf{0 . 0 0 1}$ & $40.42 \mathbf{p}<\mathbf{0 . 0 0 1}$ \\
\hline
\end{tabular}


Table 7. Statistical significance of differences in mean values of GPx by study groups—in brain homogenate.

\begin{tabular}{cccc}
\hline GPx & Lot $\mathbf{A}$ & Lot Zn & Lot Zn $+\mathbf{A}$ \\
\hline Lot $\mathbf{A}$ & - & & \\
Lot Zn & $3.22 \mathbf{p}<\mathbf{0 . 0 1}$ & - & - \\
Lot Zn $+\mathbf{A}$ & $8.54 \mathbf{p}<\mathbf{0 . 0 0 1}$ & $6.93 \mathbf{p}<\mathbf{0 . 0 0 1}$ & $9.63 \mathbf{p}<\mathbf{0 . 0 0 1}$ \\
\hline Lot $\mathbf{W}$ & $9.19 \mathbf{p}<\mathbf{0 . 0 0 1}$ & $9.32 \mathbf{p}<\mathbf{0 . 0 0 1}$ \\
\hline
\end{tabular}

Table 8. Statistical significance of differences in mean values of TAC by study groups-in serum and liver homogenate.

\begin{tabular}{c|ccccc}
\hline MDA & Lot $\mathbf{A}$ & Lot Zn & Lot $\mathbf{Z n}+\mathbf{A}$ & Lot $\mathbf{W}$ \\
\hline Lot $\mathbf{A}$ & - & $17.73 \mathbf{p}<\mathbf{0 . 0 0 1}$ & $7.76 \mathbf{p}<\mathbf{0 . 0 0 1}$ & $0.54 \mathrm{P}>0.05$ & liver homogenate \\
Lot Zn & $3.36 \mathbf{p}<\mathbf{0 . 0 0 2}$ & - & $7.34 \mathbf{p}<\mathbf{0 . 0 0 1}$ & $14.26 \mathbf{p}<\mathbf{0 . 0 0 1}$ & $6.38 \mathbf{p}<\mathbf{0 . 0 0 1}$ \\
Lot Zn + A & $3.85 \mathbf{p}<\mathbf{0 . 0 0 1}$ & $1.34 \mathrm{P}>0.05$ & - & - \\
\hline Lot $\mathbf{W}$ & $3.81 \mathbf{p}<\mathbf{0 . 0 0 1}$ & $2.42 \mathbf{p}<\mathbf{0 . 0 5}$ & $14.90 \mathbf{p}<\mathbf{0 . 0 0 1}$ & \\
& & serum & & \\
\hline
\end{tabular}

In the same group, comparing the mean values of TAC by origin of collected product, we observed that in serum these were significantly higher $(\mathrm{p}<0.001)$ compared to liver homogenate.

\section{Discussion}

The experiment aimed to investigate the influence of potential protective factors under conditions of senescence. The in vivo effect of natural polyphenols and $\mathrm{Zn}$ aspartate was studied. Five phenolic compounds have been detected in berries ethanolic extract: chlorogenic acid, kuromanin, rutin, hyperoside and quercetin [13]. By evaluating serum lipids in aged rats treated with $\mathrm{Zn}$ and $\mathrm{A}$, an extremely strong effect of TG reduction by individual substances and by the association with $\mathrm{Zn}+\mathrm{A}$ was observed. Lipoprotein abnormalities favoring dyslipidemia in senescence consist of the increase of the level of TG by means of increasing VLDL and LDL-chol and by decreasing HDL-chol due to increased HDL catabolism. Moreover, in the experiment described no effect of Aronia melanocarpa extract on elevated total cholesterol was observed.

The experimental results show that $\mathrm{Zn}, \mathrm{A}$ and $\mathrm{Zn}+\mathrm{A}$ reduce HDL-chol. The results of this study are consistent with data found in literature [14] [15]. The fraction of HDL protects against the development of atherosclerosis due to its action upon reverse cholesterol transportation and inhibition of the process of LDL oxidation [16] [17]. HDL-col protects vascular tissue against the appearance of endothelial dysfunction and subsequently against the formation of atherosclerotic plaque.

In a combined therapy, chokeberry extracts were given as supplements with the diet of patients after myocardial infarction, as an addition to the statin treatment. Compared to the control group, treated only with statins, patients receiving additional Aronia extract for 6 weeks had significantly lower LDL-chol oxidation status as well as reduced levels of serum 8-isoprostanes and increased adiponectin levels, which indicate diminished oxidative stress and reduced endothelial inflammation [18].

In our study, we observed a decrease in HDL-chol levels by administering Aronia melanocarpa in relation to control group, suggesting a decreased ability of transporting cholesterol from vascular tissue to liver, in this context, consistent with the observations in other studies [19]-[21]. Due to the fact that lipogenesis appears as a major abnormality of hepatic fatty metabolism, hepatic lipogenesis is thought to contribute to metabolic disease. De novo lipogenesis is present in human liver and predicts metabolic health. This is why it is important to determine the lipoprotein modifications in the hepatic homogenate used within the experimental model.

The average values of total cholesterol are the lowest in rats treated with $\mathrm{Zn}$, both in serum, liver homogenate, and in brain homogenate. We studied brain homogenate because lipoproteins in the brain are mostly made in the brain. Neurons and astrocytes coordinate lipoprotein metabolism in the brain and lipoprotein composition in the brain is different from that in the circulation. The effects of Aronia melanocarpa are lower compared to $\mathrm{Zn}$ and the association of $\mathrm{Zn}+\mathrm{A}$ has no cumulative effects. Understanding mechanisms by which triglyceride-rich 
lipoproteins (VLDL) activate certain transcription factors opens new perspectives to prevention and treatment of dyslipidemia and endothelial inflammation, major risk factors for endothelial dysfunction and, consequently, for neuronal functions [22] [23].

Data from literature reported an increased activity of antioxidant enzymes, superoxide dismutase (SOD) and hepatic GSH reductase suggesting a possible compensatory reaction by increasing antioxidant protection as a response to increased oxidative stress [24]-[26]. Lipid peroxidation has an important role in tissue injury. MDA is the most abundant aldehyde resulting from lipid peroxidation. As a general rule, tissue levels of free radicals, lipid peroxidation products, and antioxidants show important changes from one tissue to another with increasing age [27]. Results show that the association of A with Zn significantly reduces lipid peroxidation level, MDA values in liver and brain homogenates, respectively, less in serum. These results support the hypothesis that lipid peroxidation is one of the most harmful effects of oxidative stress, and it increases substantially in the liver being also reflected in blood.

Endogenous antioxidants such as non-enzymatic scavenger glutathione (GSH) and antioxidant enzymes such as SOD, GPx, and catalase (CAT) are the first line of defense and act by scavenging potentially damaging free radical moieties [1]. Under conditions of senescence, enzymatic markers of oxidative stress (CAT, SOD, GPx, and MDA) are augmented in serum [28].

In the current study, a significant reduction in liver GPx activity was evident in $\mathrm{Zn}+\mathrm{A}$ group, both in liver and cerebral homogenates. A and Zn reduce the levels of GPx of plasma, liver and brain homogenates compared to control group. Zn can reduce oxidative stress by binding to $\mathrm{SH}$ groups they protect. $\mathrm{Zn}$ is also a structural part of superoxide dismutase, and CuSOD and ZnSOD are cytosol antioxidants [5]. This study demonstrates that the hepatoprotective effect of $\mathrm{Zn}$, could be mainly attributed to its antioxidant action. Nevertheless, experimental results strongly suggest that the maintenance of an appropriate antioxidant/pro-oxidant balance does have an important role in maintaining health in the aging animal [29] [30].

The molecular mechanisms of the development of oxidative stress can be different in different tissues. In neuronal tissue, this process can be related to metabolism of excitotoxic compounds regulating ROS production within the neurons as well as with the shift in the functional activity of a number of proteins (for example, with activation of NMDA or monoamine oxidase $B$ ) and decreased defense provided by enzymatic and nonenzymatic antioxidants [31] [32].

Aronia melanocarpa, $\mathrm{Zn}$ and $\mathrm{Zn}+\mathrm{A}$ do not change statistically significantly TAC in serum. On the other hand, $\mathrm{Zn}$ alone has no statistically significant effect on TAC in liver homogenate. The association of $\mathrm{Zn}+\mathrm{A}$ increases significantly TAC compared to group W in liver homogenate, and A increases significantly TAC compared to group $\mathrm{W}$ in serum. The results of this study suggest that exogenous antioxidants may delay the aging process of tissues by means of its free radical scavenging effects, and might have a potential role for the retardation of age-related oxidative events [33].

The comparison of the effect of $\mathrm{Zn}$ and polyphenolic extract on age-induced liver/cerebral damage revealed that either substances may be beneficial, in spite of a mechanistic difference in the antioxidant effect of both of them. Oxidative stress assessed by MDA, GPx and TAC markers was reduced in animals receiving additional Zn salts and polyphenolic extract of Aronia melanocarpa, which underlines their role in antioxidant defense. The paper tries to transfer knowledge and results of fundamental research to applied medicine, given the growing interest for ways to reduce morbidity and mortality caused by vascular diseases and degenerative CNS by means of food supplements.

\section{Conclusion}

By reducing oxidative stress, diet supplementation with natural polyphenols and/or soluble salts of zinc, the ageing status in Wistar rats improves. Furthermore, administration of the two substances from different classes has a lipid-lowering effect, underlining the improvement of prevention strategies and senescence. Further studies will investigate the effect of different dose combinations of zinc aspartate and polyphenolic extract of Aronia melanocarpa at different periods of treatments on age-associated liver/cerebral dysfunction. This investigation into dose combinations will provide a balance of health benefits, primarily due to their antioxidant activity.

\section{References}

[1] Harman, D. (2006) Free Radical Theory of Aging: An Update: Increasing the Functional Life Span. Annals of the New 
York Academy of Sciences, 1067, 10-21. http://dx.doi.org/10.1196/annals.1354.003

[2] Youdim, K.A. and Joseph, J.A. (2001) A Possible Emerging Role of Phytochemicals in Improving Age-Related Neurological Dysfunctions: A Multiplicity of Effects. Free Radical Biology and Medicine, 30, 583-594. http://dx.doi.org/10.1016/S0891-5849(00)00510-4

[3] Cantuti-Castelvetri, I., Shukitt-Hale, B. and Joseph, J.A. (2000) Neurobehavioral Aspects of Antioxidants in Aging. International Journal of Developmental Neuroscience, 18, 367-381. http://dx.doi.org/10.1016/S0736-5748(00)00008-3

[4] Youdim, K.A., Martin, A. and Joseph, J.A. (2000) Essential Fatty Acids and the Brain: Possible Health Implications. International Journal of Developmental Neuroscience, 18, 383-399. http://dx.doi.org/10.1016/S0736-5748(00)00013-7

[5] Colvin, R.A., Fontaine, C.P., Laskowski, M. and Thomas, D. (2003) $\mathrm{Zn}^{2+}$ Transporters and $\mathrm{Zn}^{2+}$ Homeostasis in Neurons. European Journal of Pharmacology, 479, 171-185. http://dx.doi.org/10.1016/j.ejphar.2003.08.067

[6] Kitamura, H., Morikawa, H., Kamon, H., Iguchi, M., Hojyo, S., Fukada, T., Yamashita, S., Kaisho, T., Akira, S., Murakami, M. and Hirano, T. (2006) Toll-Like Receptor-Mediated Regulation of Zinc Homeostasis Influences Dendritic Cell Function. Nature Immunology, 7, 971-977. http://dx.doi.org/10.1038/ni1373

[7] Baur, J.A. and Sinclair, D.A. (2006) Therapeutic Potential of Resveratrol: The in Vivo Evidence. Nature Reviews Drug Discovery, 5, 493-506. http://dx.doi.org/10.1038/nrd2060

[8] Liu, B.L., Zhang, X., Zhang, W. and Zhen, H.N. (2007) New Enlightenment of French Paradox: Resveratrol’s Potential for Cancer Chemoprevention and Anti-Cancer Therapy. Cancer Biology \& Therapy, 6, 1833-1836. http://dx.doi.org/10.4161/cbt.6.12.5161

[9] Agarwal, B. and Baur, J.A. (2011) Resveratrol and Life Extension. Annals of the New York Academy of Sciences, 1215, 138-143. http://dx.doi.org/10.1111/j.1749-6632.2010.05850.x

[10] Demidenko, Z.N. and Blagosklonny, M.V. (2009) At Concentrations that Inhibit mTOR, Resveratrol Suppresses Cellular Senescence. Cell Cycle, 8, 1901-1904. http://dx.doi.org/10.4161/cc.8.12.8810

[11] Ohkawa, H., Ohisin, N. and Yadik, K. (1979) Assay for Lipid Peroxides in Animals Tissues by Thiobarbituric Acid Reaction. Analytical Biochemistry, 95, 351-358. http://dx.doi.org/10.1016/0003-2697(79)90738-3

[12] Parinandi, N.L., Thompson, E.W. and Schmid, H.H.O. (1990) Diabetic Heart and Kidney Exhibit Increased Resistance to Lipid Peroxidation. Biochimica et Biophysica Acta, 1047, 63-69. http://dx.doi.org/10.1016/0005-2760(90)90261-U

[13] Ciocoiu, M., Badescu, L., Miron, A. and Badescu, M. (2013) The Involvement of a Polyphenol-Rich Extract of Black Chokeberry in Oxidative Stress on Experimental Arterial Hypertension. Evidence-Based Complementary and Alternative Medicine, 2013, Article ID: 912769. http://dx.doi.org/10.1155/2013/912769

[14] Jurgoński, A., Juśkiewicz, J. and Zduńczyk, Z. (2008) Ingestion of Black Chokeberry Fruit Extracts Leads to Intestinal and Systemic Changes in a Rat Model of Prediabetes and Hyperlipidemia. Plant Foods for Human Nutrition, 63, 176182. http://dx.doi.org/10.1007/s11130-008-0087-7

[15] Frederickson, C.J., Koh, J.Y. and Bush, A.I. (2005) The Neurobiology of Zinc in Health and Disease. Nature Reviews Neuroscience, 6, 449-462. http://dx.doi.org/10.1038/nrn1671

[16] Zern, T.L., Wood, R.J., Greene, C., West, K.L., Liu, Y., Aggarwal, D., Shachter, N.S. and Fernandez, M.L. (2005) Grape Polyphenols Exert a Cardioprotective Effect in Pre- and Postmenopausal Women by Lowering Plasma Lipids and Reducing Oxidative Stress. Journal of Nutrition, 135, 1911-1917.

[17] Minamino, T. and Komuro, I. (2007) Vascular Cell Senescence: Contribution to Atherosclerosis. Circulation Research, 100, 15-26. http://dx.doi.org/10.1161/01.RES.0000256837.40544.4a

[18] Naruszewicz, M., Laniewska, I., Millo, B. and Dluźniewski, M. (2007) Combination Therapy of Statin with Flavonoids Rich Extract from Chokeberry Fruits Enhanced Reduction in Cardiovascular Risk Markers in Patients after Myocardial Infarction (MI). Atherosclerosis, 194, e179-e184. http://dx.doi.org/10.1016/j.atherosclerosis.2006.12.032

[19] Slimestad, R., Torskangerpoll, K., Nateland, H.S., Johannessen, T. and Giske, N.H. (2005) Flavonoids from Black Chokeberries, Aronia melanocarpa. Journal of Food Composition and Analysis, 18, 61-68. http://dx.doi.org/10.1016/j.jfca.2003.12.003

[20] Ishii, T., Itoh, K., Ruiz, E., Leake, D.S., Unoki, H., Yamamoto, M. and Mann, G.E. (2004) Role of Nrf2 in the Regulation of CD36 and Stress Protein Expression in Murine Macrophages: Activation by Oxidatively Modified LDL and 4-Hydroxynonenal. Circulation Research, 94, 609-616. http://dx.doi.org/10.1161/01.RES.0000119171.44657.45

[21] Mennen, L.I., Sapinho, D. and De Bree, A. (2004) Consumption of Foods Rich in Flavonoids Is Related to a Decreased Cardiovascular Risk in Apparently Healthy French Women. Journal of Nutrition, 134, 923-926.

[22] Ferrari, C.K.B. and Torres, E.A.F.S. (2003) Biochemical Pharmacology of Functional Foods and Prevention of Chronic Diseases of Aging. Biomedicine \& Pharmacotherapy, 57, 251-260. http://dx.doi.org/10.1016/S0753-3322(03)00032-5

[23] Bell, D.R. and Gochenaur, K. (2006) Direct Vasoactive and Vasoprotective Properties of Anthocyanin-Rich Extracts. 
The Journal of Applied Physiology, 100, 1164-1170. http://dx.doi.org/10.1152/japplphysiol.00626.2005

[24] Olas, B., Wachowicz, B., Nowak, P., Kedzierska, M., Tomczak, A., Stochmal, A., Oleszek, W., Jeziorski, A. and Piekarski, J. (2008) Studies on Antioxidant Properties of Polyphenol-Rich Extract from Berries of Aronia melanocarpa in Blood Platelets. Journal of Physiology and Pharmacology, 59, 823-835.

[25] Valcheva-Kuzmanova, S., Borisova, P., Galunska, B., Krasnaliev, I. and Belcheva, A. (2004) Hepatoprotective Effect of the Natural Fruit Juice from Aronia melanocarpa on Carbon Tetrachloride-Induced Acute Liver Damage in Rats. Experimental and Toxicologic Pathology, 56, 195-201. http://dx.doi.org/10.1016/j.etp.2004.04.012

[26] Rice-Evans, C.A., Miller, N.J. and Paganga, G. (1996) Structure-Antioxidant Activity Relationships of Flavonoids and Phenolic Acids. Free Radical Biology and Medicine, 20, 933-956. http://dx.doi.org/10.1016/0891-5849(95)02227-9

[27] Harman, D. (2003) The Free Radical Theory of Aging. Antioxidants \& Redox Signaling, 5, 557-561. http://dx.doi.org/10.1089/152308603770310202

[28] Rikans, L.E. and Hornbrook, K.R. (1997) Lipid Peroxidation, Antioxidant Protection and Aging. Biochimica et Biophysica Acta, 1362, 116-127. http://dx.doi.org/10.1016/S0925-4439(97)00067-7

[29] Harman, D. (2002) Free Radical Theory of Aging. Mutation Research/DNAging, 275, 257-266. http://dx.doi.org/10.1016/0921-8734(92)90030-S

[30] Rodríguez, M.I., Escames, G., López, L.C., López, A., García, J.A., Ortiz, F., Sánchez, V., Romeu, M. and Acuña-Castroviejo, D. (2008) Improved Mitochondrial Function and Increased Life Span after Chronic Melatonin Treatment in Senescent Prone Mice. Experimental Gerontology, 43, 749-756. http://dx.doi.org/10.1016/j.exger.2008.04.003

[31] Kitamura, H., Morikawa, H., Kamon, H., Iguchi, M., Hojyo, S., Fukada, T., Yamashita, S., Kaisho, T., Akira, S., Murakami, M. and Hirano, T. (2006) Toll-Like Receptor-Mediated Regulation of Zinc Homeostasis Influences Dendritic Cell Function. Nature Immunology, 7, 971-977. http://dx.doi.org/10.1038/ni1373

[32] Chrubasik, C., Li, G. and Chrubasik, S. (2010) The Clinical Effectiveness of Chokeberry: A Systematic Review. Phytotherapy Research, 24, 1107-1114. http://dx.doi.org/10.1002/ptr.3226

[33] Jou, M.J., Jou, S.B., Guo, M.J., Wu, H.Y. and Peng, T.I. (2004) Mitochondrial Reactive Oxygen Species Generation and Calcium Increase Induced by Visible Light in Astrocytes. Annals of the New York Academy of Sciences, 1011, $45-$ 56. http://dx.doi.org/10.1196/annals.1293.005 